\title{
Improving students' mathematics self-efficacy through problem based learning
}

\author{
Lisda Fitriana Masitoh ${ }^{\mathrm{a}^{*}}$, and Harina Fitriyani ${ }^{\mathrm{b}}$ \\ ${ }^{a}$ Department of Informatics Engineering, Universitas Pamulang, Tangerang Selatan, Indonesia, 15417 \\ ${ }^{b}$ Department of Mathematics Education, Universitas Ahmad Dahlan, Yogyakarta, Indonesia, 55164 \\ *Corresponding author: lisda.masitoh@gmail.com
}

\section{ARTICLE HISTORY}

Received April 13, 2018

Revised May 16, 2018

Accepted June 5, 2018

\section{KEYWORDS}

Action research

Mathematics

Problem based learning

Self-efficacy

\begin{abstract}
One of the important affective factors for students in mathematics learning is self-efficacy. The students should have high mathematics self-efficacy. So, it can support the success of learning process. The facts that indicated the low of students' mathematics self-efficacy, encouraging the efforts to improve self-efficacy through the improvement of the learning process. One of them is by applying the problem based learning approach. This research was a classroom action research by applying problem based learning approach to improve students' mathematics self-efficacy. The classroom action research was done in two cycles. Each cycle consists of planning, action, observation, and reflection. The findings of this research revealed that the problem based learning approach could improve student's mathematics self-efficacy. At the end of the first cycle, the students' mathematics self-efficacy was still in the medium category and increased at the end of the second cycle, which students' mathematics self-efficacy has been in high category.
\end{abstract}

This is an open access article under the CC-BY-SA license.

\section{INTRODUCTION}

One of the affective factors that determine the students' achievement in the learning process is self-efficacy. Bandura is the first person to reveal about self-efficacy. Bandura believes that self-efficacy is an important factor in the learning process.

Self-efficacy is judgement of a person to his capabilities to plan and implement the action to reach certain goals (Mukhid, 2009). In an academic context, self-efficacy reflects how confident students are in performing specific tasks (Perez \& Ye, 2013). Self-efficacy plays a role in academic motivation and learning motivation (especially students' ability to manage their learning activities), and resistance to learning (Zimmerman, 2000).

Self-efficacy has three dimensions that are magnitude, the level of task difficulty a person believes she can attain; strength, the conviction regarding magnitude as strong or weak; and generality, the degree to which the expectation is generalized across situations (Lunenburg, 2011). The magnitude dimension refers to the difficulty level of the task that a person believes he or she can accomplish. That is, the students' self-confidence toward their abilities in accomplishing various tasks at different levels of difficulty. The strength dimension refers to the resilience and persistence of students in accomplishing various tasks. Meanwhile, the generality dimension refers to students' beliefs about their abilities in accomplishing certain tasks as well as on a broader range of activities and situations.

Self-efficacy in mathematics is described as an individual's mathematics self-efficacy is his or her confidence about completing a variety of tasks, from understanding concepts to solving problems, in mathematics (May, 2009). High mathematics self-efficacy will encourage the achievement of good learning outcomes, and when students have good learning outcomes, they will be more motivated in the learning process. Higher self-efficacy expectations can lead to better results and therefore increase the motivation for learning mathematics (Zimmermann, et al, 2011).

Based on the description above, it can be concluded that mathematics self-efficacy is a belief or self-assessment of the student's ability in overcoming certain mathematical problems and tasks related to mathematics in the three dimensions that are magnitude, strength and generality. The dimension of magnitude refers to the students' self-confidence in their ability in overcoming the mathematical problems and tasks at different levels of difficulty. The dimension of strength refers to the resilience and persistence of students in overcoming various mathematical problems and tasks. The dimension of generality refers to students' beliefs about their ability in accomplishing certain mathematical activities as well as on a broader range of activities and situations.

Students should have high self-efficacy, so it can support the success of mathematics learning process and it can improve the student achievement. This is caused mathematics self-efficacy has a strong influence on mathematical achievement (Fast, et, al, 2015). Students with higher math self-efficacy persist longer on difficult math problems and are more accurate in math computations than those lower in math self-efficacy (Fast, et, al, 2015). Students with high self-efficacy are able to solve a problem than students with low self-efficacy. However, these expectations have not been supported by the facts. 
Based on the results of the interviews with mathematics teachers in SMP N 1 Yogyakarta, it is known that the the students self-efficacy was still relatively low. Students felt unconfident of their ability to solve math problems. Mathematics was still considered a difficult subject for students. This was supported by the results of the students' mathematics self-efficacy questionnaire that engaged 35 students.

Table 1. The Initial Conditions of Students Self-Efficacy at Class VIII-B SMP N 1 Yogyakarta

\begin{tabular}{ccc}
\hline $\begin{array}{c}\text { Number of } \\
\text { Students }\end{array}$ & Criteria of Self-Efficacy & Percentage \\
\hline 3 & Very high & $8.57 \%$ \\
\hline 9 & High & $25.71 \%$ \\
\hline 18 & Medium & $51.42 \%$ \\
\hline 5 & Low & $14.28 \%$ \\
\hline 0 & Very low & $0 \%$ \\
\hline Average & 87,94 (Medium) & \\
\hline
\end{tabular}

The table above showed that students' mathematics self-efficacy were still needs to be improved. The effort to improve student self-efficacy can be done by improving the mathematics learning process. The learning process should be organized interactively, fun, challenging and motivating the students to actively participate in the learning process. Therefore, a teacher must prepare the mathematics teaching learning activities maximally including in choosing learning approach. One of the goals is to realize the teaching learning of mathematics that can increase the students' self-efficacy.

One of the alternative learning approaches that can be used to increase students' self-efficacy is Problem Based Learning (PBL). PBL is a learning approach that uses real-world problems as a context for students to learn about problem-solving skills. As a student centered learning approach, PBL is able to provide learning conditions that are motivating, challenging and fun for students (Norman and Schmidt, 2000).

Problem Based Learning (PBL) is an instructional method where relevant problems are introduced at the beginning of the instruction cycle and uses to provide the context and motivation for the learning that fallow (Prince, 2004). Motivational learning in PBL, it is created through the presented problems at the beginning of the students' learning process. The presented problem in PBL is an unstructured problem.

Learning by using PBL is a learning strategy that is designed to improve learning by requiring students to learn the subject's material while solving the problem (Jonassen, 2011). The students' activities in overcoming the problems in PBL will make students in improving their problem solving skills. PBL uses problems as a context for students to acquire problem-solving skills and knowledge (Uden \& Beaumont, 2006). PBL is students centered, developing the active learning, motivating in learning and problem solving skills (Ali et all ,2010; Imoko \& Ajai, 2015 ).

One of the activeness in the learning process through PBL is shown through the learning process of students' group. In PBL, students work in small groups to attain the learning objectives (Botty \& Shahrill, 2015). It works in small groups and deals with real life situations (Chakrabarty \& Mohamed, 2013). Learning activities through PBL emphasizes the needs of students to investigate the presented problems and construct knowledge based on their experience. Problem Based Learning (PBL) is focused, experiential learning (minds-on, hand-on) organized around the investigation and resolution of messy, real world problem (Torp \& Sage, 2002).

The investigation process is carried out either individually or in group. The investigation engages the students actively in learning and enables for students to identify the problems; understands the problems and solves the problems, until the students gain new knowledge. The investigative process requires students to think critically, creatively and monitor their understanding (Sungur \& Tekkaya, 2006). Unstructured problem in PBL requires students to think creatively and critically (Tan, 2003). Therefore, PBL sets students as the center of learning activities and provides learning facilities for students to develop critical and creative thinking skills. In addition, PBL is convinced to increase students' confidence in their mathematical abilities (Fatade et al, 2013).

Problem based learning begins with the presentation of a problem situation and the organization of students into learning groups. Student groups are then asked to design and excute their investigations in pursuit of finding possible solutions. Students' progress is monitored by the teacher and by student themselves as the inquiries unfold. Finally, grups demonstrate their learning and engage in reflection and debriefing (Arend $\&$ Kilcher, 2010).

The use of PBL in learning mathematics is expected to facilitate students to learn actively to construct their knowledge related to math. Through PBL in mathematics learning, students can develop their thinking skills, solving problems and understanding deeper of math concepts. On the other hand, PBL provides learning motivation for students and make students feel confident in their mathematical skills. One type of questions that can be presented in a PBL is an opened ended problem. The PBL learning syntax is student orientation on issues, organizing the students to learn, guiding the individual or group investigation, developing and providing the works and analyzing and evaluating the problem solving process.

Based on the result of interviewing mathematics teachers of class VIII-B SMP N 1 Yogyakarta, it found that the learning process using PBL approach has been implemented. However, the teacher also stated that the implementation of PBL in class, especially in class VIII-B has not been maximized yet. This is caused by the cognitive ability or the students' achievement in mathematics in class VIII-B was still relatively low and the lowest among the other classes. In addition, students were also passive and less enthusiastic in engaging the mathematics learning process. Therefore, the researcher was interested to conduct a research in improving mathematics self-efficacy through Problem Based Learning at Class VIII-B SMP N 1 Yogyakarta. The PBL approach is a learning alternative that is considered capable in optimizing and improving students' self-efficacy. In implementing of learning using PBL approach, the students will be able to learn from the real problems that occur in real life. Next, the students can do the investigation individually or in group to solve the problems so that the students obtain new knowledge or in another word the students construct their knowledge by themselves.

Through mathematics learning using PBL approach, students will be accustomed to solve matematics problems and be responsible for the results. When students are accustomed in solving math problems by themselves, it is expected that students' belief in their mathematical ability will increase. With the potential of the PBL, students' mathematics self-efficacy is expected to increase. 


\section{METHOD}

The type of this research was Classroom Action Research. Classroom action research conducted collaboratively between researchers and mathematics teacher of class VIII-B SMP N 1 Yogyakarta. The subject of the study was the students of class VIII-B SMP N 1 Yogyakarta that consisting of 35 students.

The focus of Classroom Action Research was on alternative actions through Problem Based Learning approach that is planned by researchers in cooperation with teacher in order to achieve the goal of the research. That was to improve the learning process in the class and the students' mathematics self efficacy of class VIII-B SMP N 1 Yogyakarta. Furthermore, an action evaluation was conducted to find out whether the action can provide the improvements in the learning process and improve the students' mathematics self efficacy or not.

The design of this research used a classroom action research design developed by Kemmis and Taggart. According Kemmis and Taggart (1988), "action reseach is cyclic process of planning, action, observation, and reflection". The research design of Kemmis and Taggart models is illustrated through several cycles and each cycle consists of four stages.

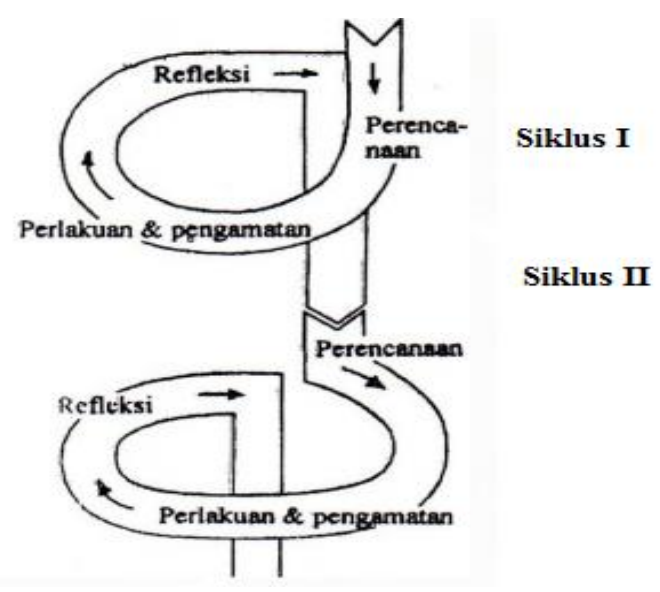

Fig 1. Design Action Research by Kemmis and Taggart

The Kemmis and Taggart models are basically strands where one string consists of planning, action, observation, and reflection. The number of cycles in a research depends on the problem solved. The more complex a problem the more cycles will be implemented. The research was conducted in several cycles, with the purpose to know the progress of the improvement and to perform the stages of improvement well. Each cycle has several stages: planning, action, observation and reflection.

\subsection{Technique of Data Collection}

The collecting data of this research were questionnaires, tests, observations, and interview. Questionnaire was used to measure the students' mathematics self-efficacy of class VIII-B SMP N 1 Yogyakarta. Questionnaire was derived from five scales. The test was used to measure mathematics learning achievement of students at class VIII-B SMP N 1 Yogyakarta. Observation was used to observe the implementation of the planned lesson. The observation was performed by an observer. The interview was conducted by the researcher to the mathematics teacher of class VIII-B SMP N 1 Yogyakarta to know the initial condition or the characteristics of the students of class VIII-B SMP N 1 Yogkayarta. Meanwhile, the documentation was done to strengthen the data obtained in the observation.

\subsection{Technique of Data Analysis}

The data of the research were analyzed descriptively in each cycle. The analyzing data was used to determine the implementation of mathematics learning using PBL approach. The analyzed data was obtained during the research. There were data of self-efficacy questionnaire, data of achievement test and data of observation of learning implementation in each cycle

The data of self-ffficacy questionnaire was analyzed by changing the mean score of each assessment to a qualitative score based on the five-scale rating criterion (Azwar, 2010).

Table 2. The Conversion of Self-Efficacy Score

\begin{tabular}{cc}
\hline Score Interval & Criteria \\
\hline $\mathrm{X}>\mathrm{Xi}+1,5 \mathrm{SBi}$ & Very high \\
\hline$X i+0,5 \mathrm{SBi}<\mathrm{X} \leq X i+1,5 \mathrm{SBi}$ & High \\
\hline$X i-0,5 \mathrm{SBi}<\mathrm{X} \leq X i+0,5 \mathrm{SBi}$ & Medium \\
\hline$X i-1,5 \mathrm{SBi}<\mathrm{X} \leq X i-0,5 \mathrm{SBi}$ & Low \\
\hline $\mathrm{X} \leq \bar{x} i-1,5 \mathrm{SBi}$ & Very low \\
\hline
\end{tabular}

Where :

$\mathrm{Xi} \quad=(1 / 5) \times($ ideal maximum score + ideal minimum score $)$

$\mathrm{SBi}=(1 / 6) \times$ (ideal maximum score - ideal minimum score $)$

The data of learning achievement test were analyzed to conclude the percentage of students who passed the test. The students who passed the test if they got the minimum score, it was 75 which is suitable with the minimum score in SMP N 1 Yogyakarta. The Indicators of the success of the classroom action research are:

1. There was an increasing the average score of students' self-efficacy at class VIII-B SMP N 1 Yogyakarta. It means that the mean score in initial condition of students' mathematics self-efficacy is 87.94 (medium category) increased to be 90 (high category). The percentage of students who have very high self-efficacy reached $15 \%$, and high self-efficacy reached $50 \%$.

2. There was an increasing percentage of students who achieved the completeness in the learning achievement test, it was $70 \%$ students who passed the test. The students who got the minimum score (75) in the learning achievement test, she or he passed the test.

3. The implementation of mathematics learning using Problem-Based Learning Approach which obtained by the observation sheets reached $85 \%$.

\section{RESULTS AND DISCUSSION}

This classroom action research was carried out in two cycles. At the beginning in each cycle, students did a pretest to know the students' basic skills. The implementation of the teaching learning process which using work sheets that has been prepared by researchers and given to each student. The students discussed in small group discussions of 2-4 students. However, work sheets was given for each student, so that all students have the same learning experience in doing the tasks in work sheets. At the end of each cycle, the students were given a posttest that aimed to measure students' achievement and observed the achievement of research targets. The classroom action research which carried out using a problem-based learning model, in each cycle included four stages. They were planning, action, observation and reflection. Classroom action 
research by applying Problem Based Learning (PBL) approach in mathematics learning conducted at class VIIIB SMP N 1 Yogyakarta has done agreeing with the plan and has reached the target that set at the beginning of the research.

The process of learning mathematics in the first cycle has not run maximally yet because the students was still need adaptation with the researchers and students were still not familiar with problem based learning. The conditioning of students was still not maximal; some students sometimes were busy with the out of topics of the material and playing with their gadgets. There were some students who still lack of focus in engaging the learning. However, they were still willing to accept the advice or warning from the teacher and researchers. In the discussion, there were still students who were not active in the group. It was also found the students who found difficulties in learning process, so they needed more guidance from the teacher. In the presentation activity, students were still unconfident to express their ideas. In the initial meeting the teacher referred directly, so that students want to convey the results of the discussion. However, these conditions began to overcome and change when entering in the second cycle.

Overall, the implementation of mathematics learning usingthe PBL approach has proceeded in accordance with the plan. Target of the research related to the implementation of the learning process has been achieved. The implementation of learning has reached more than $85 \%$.

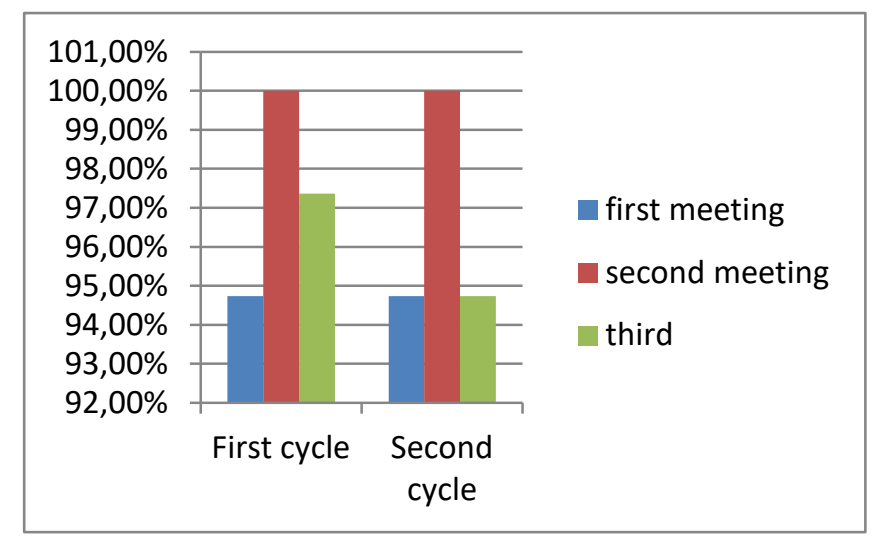

Fig 2. The Implementation of the Learning Process of The First Cycle and The Second Cycle

The main research target that was self-efficacy has also been achieved. The increasing of students' mathematics self-efficacy of class VIII-B SMP N 1 Yogyakarta is presented in the following figure.

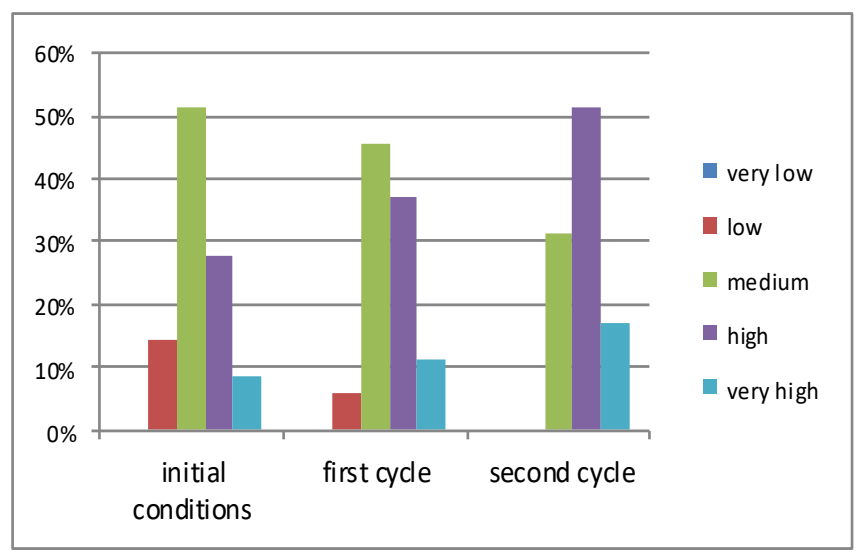

Fig 3. The improvement of Students' Mathematics Self-Efficacy
Students' learning achievement was measured by test instrument. In this research, there were four tests, namely pretest and postest in the first cycle; pretest and postest in the second cycle. The target of research related to the students' mathematics learning achievement of classVIII-B SMP N 1 Yogyakarta based on the completion percentage presented in the following figure.

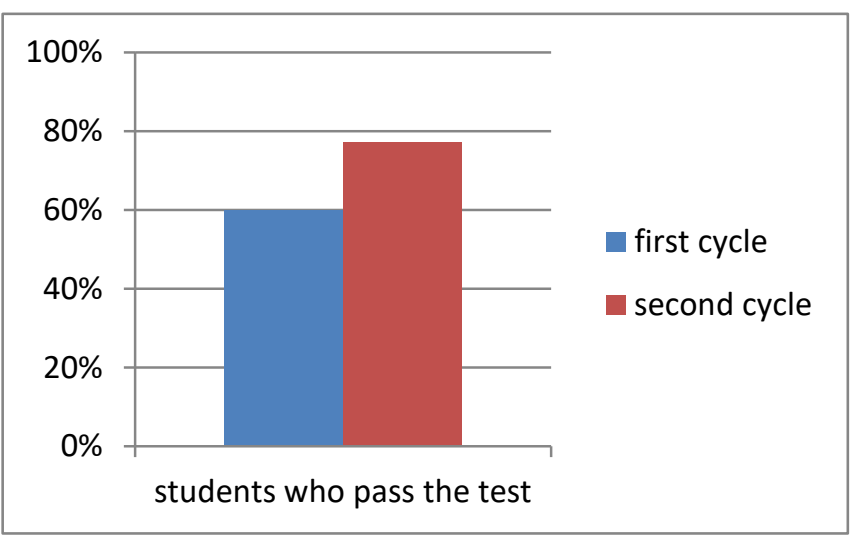

Fig 4. Percentage of Student Learning Completion

From the obtained data revealed that classroom action research that conducted collaboratively between researchers and teacher of mathematics of class VIII-B SMP N 1 Yogyakarta can improve students' mathematics self-efficacy.

\section{CONCLUSION}

Based on the analysis results of the implementation of Problem Based Learnng (PBL) approach in mathematics learning process, the students' mathematics self-efficacy questionnaire and the students' mathematics achievement test of class VIII-B SMP N 1 Yogyakarta can be drawn the conclusions as follows:

1. The implementation of Problem Based Learning (PBL) approach in mathematics learning process has reached more than $85 \%$. The implementation in the first cycle reached $97.368 \%$. Meanwhile, in the second cycle, it reached $96.491 \%$.

2. There were $60 \%$ of students who have passed in the achievement test with the mean score 68.46 at the end of first cycle. This result increased in second cycle, there were $77.14 \%$ of students who have passed the achievement test with the mean score 77.86 .

3. At the end of first cycle, students' mathematics self-efficacy was still in the medium category with the mean score 89.77. This result increased at the end of second cycle, where students' mathematics self-efficacy has been in the high category with the mean 93.31 .

\section{REFERENCES}

Ali et al. (2010). Effect of using problem solving method in teaching mathematics on the achievement of mathematics students. Asian Social Science, 6(2), 66-72.

Arends \& Kilcher, A. (2010). Teaching for student learning: Becoming an accomplished teacher. New York, NY: Taylor \& Francis Group.

Azwar, S. (2010). Tes prestasi. Yogyakarta: Pustaka Pelajar.

Botty, H. M. R. H., \& Shahrill, M. (2015). Narrating a teacher's use of structured problem-based learning in a mathematics lesson. Asian Journal of Social Sciences \& Humanities, 4(1), 156-164.

Chakrabarty, S., \& Muhamed, N. (2013). Problem based learning: 
Cultural diverse students' engagement, learning and contextualized problem solving in a mathematics class. Wcik E-Journal of Integration Knowledge, 38-49.

Fatade, A. O., Mogari, D., \& Arigbabu, A. A. (2013). Effect of problem-based learning on senior Secondary school students' achievements in Further mathematics. Acta Didactica Napocensia, 6 (3), 29-44.

Fast, L. A. et. al. (2015). Self-efficacy and standardized test performance. Accessed on 22 November 2017 of http://rap.ucr.edu/efficacy.pdf

Fonna, M., \& Mursalin, M. (2018). Role of Self-Efficacy Toward Students' Achievement in Mathematical Multiple Representation Ability (MMRA). Jurnal Ilmiah Peuradeun, 6(1), 31-40.

Imoko, B. I., \& Ajai, J. T. (2015). Gender differences in mathematics achievement and retention score: A case of problem based learning method. International Journal of resecarch in Education and Science, 1 (1), 45-50.

Jonassen. (2011). Learning to solve problem: A handbook for designing problem solving learning environments. New York, NY: Routledge.

Kemmis, S. and R McTaggart.(1988). Action Research - some ideas from The Action Research Planner, Third edition, ed. Deakin University.

Lunenburg, F. C. (2011). Self efficacy in the workplace: impilication for motivation and performance. International Journal of Management, Bussissnes, and Administratiol, 14(1), 1-6.

May, D. K. (2009). Mathematics self-efficacy and anxiety questionnaire. (Doctor of Philosophy Disertation, University of Georgia)

Mukhid, A. (2009). Self-efficacy: perspektif teori kognitif sosial dan implikasinya terhadap pendidikan. Journal Tadris, 4(1), 106-122

Norman, G. R., \& Schmidt, H. G. (2000). Effectiveness of problem-based learning curricula: theory, practice and paper darts. Medical Education, 34, 721-728.

Perez, E. D., \& Ye, Y. (2013). The relationship between mathematics self-efficacy and mathematics achievement of mathayomsuksa students in the english program of st. Joseph bangna school. Assumption Journal, 5(2), 82-92.

Prince, M.(2004). Does active learning work? A review of the research. Journal of Engineering Education. 93(3), 223-231.

Sungur, S., \& Tekkaya, C. (2006). Effect of problem based learning and traditional instruction on self-regulated learning. The Journal of Educational Research, 99(5), 318-317.

Tan, O. S. (2003). Problem-based learning innovation: using problems to power learning in the 21 st century. Singapore: Cengage Learning.

Torp, L., \& Sage, S.(2002). Problem as possibilities: Problem based learning for K-16 education (2nd ed). Alexandria, VA: ASCD

Uden, L., \& Beaumont, C.( 2006). Technologi and problem based learning. Hershey, PA: Idea Group.

Zimmerman, B. J. (2000). Self efficacay: An essential motive to learn. Contenporary educational Psychology, 25, 82-9.

Zimmerman, M., Bescherer, C., \& Spannagel, C. (2011). A questionaire for surveying mathematics self-efficacy expectations of future teachers. Accessed on 14 July 2017.

http:/ / www.cerme7.univ.rzeszow.pl/WG/14/CERME7-WG14-Paper---Z immermann,-Bescherer-\&-Spannagel-REVISED-Dec201 .pdf

License information: This is an open-access article distributed under the terms of the Creative Commons Attribution License, which permits unrestricted use, distribution, and reproduction in any medium, provided the original work is properly cited. 